\title{
HEARING EVALUATION AFTER MYRINGOPLASTY AT NEPAL MEDICAL COLLEGE AND TEACHING HOSPITAL
}

\section{Rupesh Raj Joshi, Anil Kumar Jha, Anupama Shah Rijal, Anup Dhungana and Kundan Kumar Shrestha}

\begin{abstract}
Objective: To evaluate the graft takes rate of the myringoplasties performed by underlay technique using temporalis fascia graft for the last one year and to assess the hearing improvement in the successfully operated cases.
\end{abstract}

Methods: This prospective Study included 52 ears of 50 patients, who underwent myringoplasty. All operations were performed using an underlay technique and mostly by postaural approach. In all the cases, temporalis fascia was used for the reconstruction of TM. The data of all the patients regarding preoperative disease, perforation size and localization, surgical approach, graft material, pre- and postoperative clinical and functional (hearing evaluation by pure-tone audiogram) results were analyzed.

Results: Successful closure rate of the TM perforation was $82.69 \%$ and the graft failure rate was $17.30 \%$. In this study, lowest and highest age of patients at presentation was 12 and 42 years respectively with a mean age of 25.5 years. The success rate was better with the advancing age. The most common approach was postaural. Medium size and posterior perforations were common and the graft take rate was $80.95 \%$, and $88.89 \%$ respectively. The mean pre and post-operative air conduction threshold in the successful cases were $38.69 \mathrm{~dB}$ and $30.35 \mathrm{~dB}$ respectively with a mean audiological improvement of around $8 \mathrm{~dB}$. The improvement in the hearing was achieved in only $67.44 \%$ (29 out of 43) among the successful operated myringoplasties.

Conclusion: Myringoplasty is a safe and effective technique to improve the quality of life of patients. The most common approach was postaural. The graft takes rate was better with the advancing ages and with the medium size and posterior perforations. The improvement in hearing was also achieved.

Keywords: Myringoplasty, Graft takes rate, Hearing improvement.

\section{Introduction}

In all developing countries the incidence of chronic suppurative otitis media (CSOM) is very high because of poor socioeconomic standard, overcrowding, poor nutrition and lack of health education ${ }^{1}$.

Among the two types of chronic suppurative otitis media, Tubotympanic disease is characterized by a perforation of the pars tensa of varying size and shape but with a narrow margin of intact annulus. Patients with this form of otitis media are generally not considered to be at risk of developing complications such as intracranial sepsis. The term 'safe' otitis media is often applied to this condition. ${ }^{2,3}$. 
The patients always present with aural discharge with or without hearing loss. Aural discharge is always mucoid or mucopurulent and varies with upper respiratory tract infection. Discharge is usually intermittent recurring whenever there is a upper respiratory tract infections or water enters in to the ear ${ }^{4}$.

Hearing loss in tubotympanic disease is usually conductive in nature but a few case of sensorineural hearing loss is also found ${ }^{3}$. Hearing loss with intact ossicular chain is approximately 10-30 dB. ${ }^{5,6}$ But more when ossicular chain is disrupted.

Myringoplasty is the operation specially designed to repair or reconstruct the tympanic membrane. From the seventeenth to the nineteenth centuries, several attempts at closing tympanic membrane perforations using prosthetic materials were made, culminating in the "paper patch" technique developed by Blake in 1887. The use of cauterizing agents to promote healing of tympanic membrane perforations was introduced by Roosa in 1876, who used the application of silver nitrate to the rim of a perforation. ${ }^{7}$

The surgical repair of permanent tympanic membrane perforations was first attempted at the same time as the paper patch technique but did not produce adequate results until 1952, when Wullstein published a method of closing perforations with a split-thickness skin graft. ${ }^{8}$ Zöllner also described his experiences with a similar graft. ${ }^{9}$ After introduction of the use of the operating microscope by Wullstein and Zöllner,there was significant enhancement in the surgical results by improving the accuracy of the technique.

Zöllner first used fascia lata to close perforations. ${ }^{10}$ In 1958, Heermann began to use temporalis fascia. ${ }^{11}$ In 1960, Shea first described the closure of tympanic membrane perforations by underlay technique using a vein graft. ${ }^{12}$
In the 1960s and 1970s, homograft (cadaveric) materials, including tympanic membrane, dura, and pericardium, among others, were used with varying success. Since then, myringoplasty has gone through many changes in technique and materials. None of these materials gained universal acceptance and today pose a problem because of the potential for transmitting disease (eg, Jakob-Creutzfeldt disease and HIV infection).Temporalis fascia continues to be the material of choice for reconstruction of the tympanic membrane. ${ }^{7}$

The surgical outcome of myringoplasty is influenced by many factors. The reported success rate of myringoplasty is therefore variable, partly because of differences in the inclusion and exclusion criteria. In a study overall success rate of myringoplasty was $86 \%$. Posterior and inferior perforations had a $98 \%$ success rate for repair compared to only $67 \%$ of anterior perforation. The success rates of subtotal perforations closure were $92.5 \%{ }^{13}$.

Regardless of the technique employed, take rates of 93 to $97 \%$ are typically reported. ${ }^{14,15}$.

A study found better success with advancing age $^{16}$. This is due to lower incidence of upper airway infection and better Eustachian tube function in later age and the relative immaturity of system in younger children.

At present, myringoplasty is a common operation in the Otolaryngology Department, having microsurgical facilities.

This study aims to evaluate the surgical and audiological outcome of myringoplasties done in the cases of chronic otitis media, mucosal, inactive type, by underlay technique with temporalis fascia graft.

\section{Materials and Methods}

This prospective study was carried out in the department of ENT and Head- Neck surgery of 
NMCTH, Jorpati, from October 2011 to September 2012.

In this prospective study, 52 ears of the 50 patients were considered who underwent myringoplasty using underlay technique with temporalis fascia graft. Two patients were operated bilaterally. Each ear was considered separately. After taking relevant history, clinical examination and investigation, the diagnosis was made and considered for the operation. After written consent, the operations were done by senior residents or consultants either under general or local anaesthesia. The cases were followed up at least for three months.

\section{Inclusion criteria:}

(a) CSOM- Tubo tympanic type with dry central perforation for at least 3 weeks without any other external ear, middle ear or inner ear diseases.

(b) No evidence of cholesteatoma.

(c) Uncomplicated.

(d) Age between 12 to 45 years.

\section{Exclusion criteria:}

(a) Evidence of cholesteatoma.

(b) Previous ear surgery.

(c) Traumatic perforation.

(d) Severe Tympanosclerosis .

(e) Only hearing ear. (f) Chronic otitis externa.

(g) Systemic diseases: Diabetes Mellitus, Tuberculosis.

The patients were post operatively followed up at weekly interval for 1 st month and Then at the period of three months. Result of surgery was regarded as successful if ear was dry and the tympanic membrane intact and mobile at the end of three months follow up. Pure tone Audiograms were performed at three months and hearing gain or loss was compared with pre-operative test.

\section{Results}

Table 1: Graft takes rate

\begin{tabular}{|l|l|l|}
\hline \multicolumn{1}{|c|}{ Tympanic membrane } & \multicolumn{2}{|c|}{ No. of ears } \\
\hline Graft take (intact \& Mobile) \\
\hline \multirow{5}{*}{ Graft failure } & $\begin{array}{l}\text { Complete } \\
\text { graft failure }\end{array}$ & 2 \\
\cline { 2 - 3 } & Medialization & 3 \\
\cline { 2 - 3 } & $\begin{array}{l}\text { Residual } \\
\text { perforation }\end{array}$ & 4 \\
\hline
\end{tabular}

Table-I show that overall grafts were successfully taken in 43 ears $(82.69 \%)$ and graft failure was seen in 9 ears $(17.30 \%)$, amongst which complete failure of graft was in 2 ears $(3.85 \%)$, medialization in three $(5.77 \%)$ and the residual perforation in 4 ears $(7.70 \%)$.

Table 2: Age distribution with relative frequency of graft takes rate in different age groups

\begin{tabular}{|c|c|c|c|}
\hline Ages & $\begin{array}{c}\text { no. of } \\
\text { ears }\end{array}$ & $\begin{array}{c}\text { Graft } \\
\text { intake }\end{array}$ & $\begin{array}{c}\text { Graft } \\
\text { failure }\end{array}$ \\
\hline $10-20$ & 22 & 17 & 5 \\
\hline $21-30$ & 15 & 12 & 3 \\
\hline $31-40$ & 10 & 9 & 0 \\
\hline$>40$ & 5 & 5 & 1 \\
\hline
\end{tabular}

In this study maximum patients were noted in the first decade but the graft takes rate was least in this age group. The age of the youngest patient was 12 year and age of the oldest patient was 42 years. The mean age was around 
25.5years. Graft take rate of $77.27 \%$ was seen in the age group of $11-20$ years and $80 \%$ was seen in 21-30years. Graft take rate of $90 \%$ was seen in 31-40yrs. Graft take rate of $100 \%$ was seen in above 40 years of age group.

Table 3: Relative frequency of graft takes rate in relation to the size of perforation

\begin{tabular}{|l|c|c|c|}
\hline \multicolumn{1}{|c|}{ Size } & $\begin{array}{c}\text { No. of } \\
\text { ears }\end{array}$ & $\begin{array}{c}\text { Graft } \\
\text { intake }\end{array}$ & $\begin{array}{c}\text { Graft } \\
\text { failure }\end{array}$ \\
\hline Small & 16 & 15 & 1 \\
\hline Medium & 21 & 17 & 4 \\
\hline Subtotal & 15 & 11 & 4 \\
\hline
\end{tabular}

Medium sized perforations were most common in this study and the graft take rate in this group was $80.95 \%$. Graft take rate of subtotal perforation was $73.33 \%$. The graft take rate of small size perforation was highest $(93.75 \%)$

Table 4: Relative frequency of graft takes rate in relation to the site of perforations

\begin{tabular}{|l|l|}
\hline Pre-op AC (dB) & no. of ears \\
\hline A.0-25 & 1 \\
\hline B. $26-40$ & 22 \\
\hline C. $>40$ & 20 \\
\hline Mean(dB) & 38.69 \\
\hline
\end{tabular}

The graft take rate in case of posterior and anterior perforation were $88.89 \%$ and $84.21 \%$ respectively which was significantly more than that of subtotal perforation $73.33 \%$.
Table 5: Surgical approach

\begin{tabular}{|l|l|l|l|}
\hline Approach & $\begin{array}{c}\text { No. of } \\
\text { ears }\end{array}$ & $\begin{array}{c}\text { Graft } \\
\text { intake }\end{array}$ & $\begin{array}{c}\text { Graft } \\
\text { failure }\end{array}$ \\
\hline Postaural & 40 & 35 & 5 \\
\hline Endaural & 5 & 3 & 2 \\
\hline Transcanal & 7 & 5 & 2 \\
\hline
\end{tabular}

Above table shows that most common approach was postaural $76.92 \%$, followed by transcanal approach $13.46 \%$. The graft take rate of the postaural was $87.5 \%$ and for the transcanal was $71.43 \%$ and for endaural, it was $60 \%$.

Table 6(a): Audiological results in successful cases-Preoperative air conduction threshold

\begin{tabular}{|l|c|c|c|}
\hline \multicolumn{1}{|c|}{ Site } & $\begin{array}{c}\text { No. of } \\
\text { ears }\end{array}$ & $\begin{array}{c}\text { Graft } \\
\text { intake }\end{array}$ & $\begin{array}{c}\text { Graft } \\
\text { failure }\end{array}$ \\
\hline anterior & 19 & 16 & 3 \\
\hline posterior & 18 & 16 & 2 \\
\hline subtotal & 15 & 11 & 4 \\
\hline
\end{tabular}

Table 6(b): Audiological results in successful cases-Postoperative air conduction threshold:

\begin{tabular}{|l|l|}
\hline \multicolumn{1}{|c|}{ Post-op AC (dB) } & \multicolumn{1}{c|}{ No. of ears } \\
\hline A.0-25 & 11 \\
\hline B. $26-40$ & 28 \\
\hline C. $>40$ & 4 \\
\hline Mean(dB) & 30.35 \\
\hline
\end{tabular}

The ears which were having air conduction of $26-40 \mathrm{Db}$ and more than $40 \mathrm{~dB}$ were become better post-operatively and shifted to the 0 - 
$25 \mathrm{~dB}$ and $26-40 \mathrm{Db}$ groups, so that there were more cases in $0-25 \mathrm{~dB}$ and less number of cases in more than 40 groups post-operatively.

Table 6(c): Audiological results in successful cases-Air bone gap in pure tone audiometry of the patients those underwent myringoplasty

\begin{tabular}{|l|l|}
\hline AB Gap & Mean dB \\
\hline Pre-op & 25 \\
\hline Post-op & 15 \\
\hline $\begin{array}{l}\text { Change in AB } \\
\text { gap }\end{array}$ & 10 \\
\hline
\end{tabular}

Table VI $(a, b, c)$ shows that mean preoperative and postoperative air conduction threshold in successfully operated ears were $38.79 \mathrm{~dB}$ and $30.35 \mathrm{~dB}$ respectively. Improvement of air bone gap was around $10 \mathrm{~dB}$.

Table 7: Hearing improvement

\begin{tabular}{|l|l|}
\hline Outcome & No. of ears \\
\hline Improvement & 29 \\
\hline No improvement & 14 \\
\hline
\end{tabular}

Above table shows that hearing gain occurred in 29 ears $(67.44 \%)$ and no improvement seen in $14(32.56 \%)$ ears.

\section{Discussion}

In this prospective study, 52 ears of 50 patients were considered. They underwent myringoplasty using underlay technique with temporalis fascia graft after taking relevant history, clinical examination and investigation and followed up for at least three months.

In this series the graft take rate was $82.69 \%$ (43/ 52) and the graft failure rate was $17.30 \%$. $(9 / 52)$. The rate of graft intake of this study is more or less similar to the Kotecha $(82 \%)$ but less than Ugo Fish (86\%). ${ }^{\mathbf{1 7} 18}$ Eero Vartiainen showed that the rate of graft intake was $91.2 \%$, which was significantly higher than this study. ${ }^{19}$

In this study, lowest and highest age of patients at presentation was 12 and 42 years respectively with a mean age of 25.5 years. Patient's age has generally considered as influencing surgical outcome. Graft take rate of $77.27 \%$ was seen in the age group of $11-20$ years and Graft take rate of $80 \%, 90 \%$ and $100 \%$ seen in age group of 21-30 years, 3140years and above 40 years respectively. In this series, the success rate is better with the advancing age as found by the Vrabec et al. ${ }^{16}$ This is due to low incidence of upper airway infections and better Eustachian tube function in this age and the relative immaturity of the immune system in younger children.

Medium sized perforations were most common in this study and the graft take rate in this group was $80.95 \%$.Graft take rate of subtotal perforation was $73.33 \%$. The graft take rate of small size perforation was highest and it was $93.75 \%$.

One series showed that the closure rate was reported to be higher in small perforations $(74 \%)$ than large perforations $(56 \%) .^{\mathbf{2 0}}$ In this study graft take rate in case of posterior and anterior perforation were $88.89 \%$ and $84.21 \%$ respectively which was significantly more than that of subtotal perforation $73.33 \%$.

Higher rate of surgical failure in patients with anterior perforations in comparison to posterior perforations in this study may have been due to the more limited vascularization of the anterior part of the ear drum, limited access to this perforation as well as difficulty in graft placement. The site of perforation statistically affecting the outcome of the surgery was also previously reported by others ${ }^{\mathbf{2 1 , 2 2}}$.

Surgical approach depended on dimension of external auditory canal, site of perforation as 
well as surgeon's preferences. In our institute we were more comfortable with the post aural approach.

In this study, the most common approach was postaural $76.92 \%$ followed by transcanal approach $13.46 \%$. The graft take rate for the postaural was $87.5 \%$ and for the transcanal was $71.43 \%$ and for endaural, it was $60 \%$. However other series found no difference of graft in take in relation to approach used. ${ }^{23}$.

The mean pre and post-operative air conduction threshold in the successful cases were $38.69 \mathrm{~dB}$ and $30.35 \mathrm{~dB}$ respectively with a mean audiological improvement of around 8 $\mathrm{dB}$. Improvement of mean air-bone gap was 10 $\mathrm{dB}$.

The best improvement was observed at the frequency of 250-1000 Hz. The improvement in the hearing was achieved in only $67.44 \%$ (29 out of 43) among the successfully operated cases.

Lee et al and Palva and Ransay stated that mean hearing improvement was $8 \mathrm{~dB}$ in their

\section{References:}

1. Ludman H. Reconstruction's of the middle ear. In: Mawason's Diseases of the ear, 6th edn, London, Edward Arnold, 1998: 432-33.

2. R. P. Mills. Management of chronic suppurative otitis media. In: John B. Booth, Editor, ScottBrown's Otolaryngology, 6th ed. London: Butterworth, 1997: 1-11.

3. Ludman H. Applied anatomy In: Mawson's Diseases of the Ear, 5th ed. London, Edward Arnold, 1988: 17-25.

4. Caylan R, Titiz A, Falcioni M, De Donato G, Russo A, Taibah AA, et al. Myringoplasty Children: Factors influencing surgical outcome. Otolaryngol Head Neck Surg 1998; 118: 709-13. series, this improvement similar to our study ${ }^{\mathbf{2 0}}$, 24

In most case of chronic suppurative otitis media, even though the ossicular chain may appear normal, there is some factor of scar tissue that prevents total restoration of hearing. ${ }^{25}$

In this series, 14 out of 43 successful cases $(32.56 \%)$ did not show in which hearing was not improved significantly after surgery despite having the eardrum heal perfectly and the middle ear remain aerated. This is similar to the study that was done by Ugo Fish, who found that the hearing improvement occurred in $66 \%$ patient.

\section{Conclusion:}

Myringoplasty is a safe and effective technique to improve the quality of life of patients. The most common approach was postaural. The graft takes rate was better with the advancing ages and with the medium size and posterior perforations. The improvement in hearing was also achieved.

5. Gray RF, Hawthorne M. In: Synopsis of Otolaryngology, 5th edn. London: ButterworthHeinemann,1992: 3-117.

6. Anthony WP. Harrison CM. Tympanice membrane perforation: Effect on audiogram. Arch Otolaryngology 1972; 95: 506-10.

7. Spiros Manolidis. Closure of Tympanic Membrane Perforations. In: Glasscock ME III \& Gulya AJ, Editors, Glasscock- Shambaugh: Surgery of the Ear $5^{\text {th }}$ ed. Hamilton: BC Decker, Inc, 2003

8. Wullstein H. Funktionelle Operationen im Mittelohr mit Hilfe des freien Spalt- lappenTransplantates. Arch Ohren- Nasen-uKehlkopfh 1952;161:422.

9. Zollner F. The principles of plastic surgery of the sound conducting apparatus.J Laryngol Otol 1955;69:637. 
10. Zollner F. Panel of myringoplasty. Second workshop on reconstructive middle ear surgery. Arch Otol 1963;78:301.

11. Heermann H. Tympanic membrane plastic with temporal fascia. Hals-Nasen-Ohrenh 1960;9:136.

12. Shea JJ. Vein graft closure of eardrum, perforations. J Laryngol Otol 1960; 74:358.

13. Yung-MW. Myringoplasty for subtotal perforation. Clin-Otolaryngol. 1995; 20(3): 241-5.

14. Glasscock ME III, Jackson CG, Nissen AJ, Schwaber MK. Postauricular Undersurface tympanic Membrane grafting: a follow-up report. Laryngoscope 1982;92:718-27.

15. Sheehy JL, Anderson RG. Myringoplasty. A review of 472 cases. Ann Otol Rhinol Laryngol 1980;89:331-4.

16. Vrabec JT, Deskin RW,Grady JJ. Metaanalysis of pediatric tympanoplasty. Arch Otolaryngol Head Neck Surg 1999;125: 530-4.

17. Kotecha-B; Fowler-S. Myringoplasty: a prospective audit study Clin-Otolaryngol. 1999; 24(2): 126-9.
18. Fish U. Tympanoplasty, mastoidectomy and stapes Sugery, J Laryngol Otol 1994; 39: 44-49.

19. Vartiainen E. Succes and pitfalls in Myringoplasty: The Am J Otol. 1996; 14 (3): 145-8.

20. Lee p, Kelly G, Mills RP. Myringoplasty : does the size of perforation matter ? Clinical Otolaryngology and Allied Sciences. 2002; 27: 331-4.

21. Mackinnon D. Relationship of preoperative Eustachian tube function to myringoplasty. Acta otolagygol (stock) 1970; 35: 100-106.

22. Prasnsuk $\mathbf{S}$ and Hinchelffe R. Tympanic membrane perforation: Descriptors and hearing levels in otitis media. Audiology 1982; 21: 43-51.

23. Wright A. Anatomy and ultra stucture of the human ear. In: Wright D, Editor, Scott- Brown's Otolaryngology, 5th ed. London: Butterworths, 1987: 6-25.

24. SpalvaT, Ramsay H. Myringoplasty and tympanoplasty-results related to training and experience. Clinical Otolaryngology and Allied Sciences. 1995; 20: 329-35.

25. Koch WM, Friedman E, Mc Gill TJI, Healy GB. Tympanoplasty type 1. Arch Otolaryngol Head Neck Sug 1990; 116: 35-40.

Address for correspondence: Rupesh Raj Joshi, Department of ENT \& HNS, Nepal Medical College and Teaching Hospital, Atterkhel, Jorpati. Email:dr.rupesh123@yahoo.com 